\title{
ENGLISH SPYCRAFT PROFESSIONALISMS AS A LINGUISTIC PHENOMENON
}

\author{
Oleksandr Lahodynskyi \\ Military Diplomatic Academy named after Yevheniy Bereznyak, Kyiv, Ukraine \\ berezan2016@meta.ua \\ Kostyantyn Mamchur \\ Military Diplomatic Academy named after Yevheniy Bereznyak, Kyiv, Ukraine \\ konstantynmtcplttc@gmail.com \\ Volodymyr Skab \\ Military Diplomatic Academy named after Yevheniy Bereznyak, Kyiv, Ukraine \\ tesoro@i.ua
}

\begin{abstract}
The article defines and classifies English Spycraft professionalisms (ESP) as lexical units denoting main espionage concepts. It establishes that, because of inconsistency with the 'terminology' requirements (basically, lack of exact definitions, abundance of synonyms, and connotation colourings), these lexical units can be placed only under 'professionalisms' category. They include vocabulary with various degrees of formality: from official to very colloquial. The article also provides detailed ESP morphological and semantic analyses. Morphology demonstrates the three basic groups of ESP building means: compounding (formation of ESP complex phrases with several words of different parts of speech), affixation (using prefixes and suffixes), and abbreviation (shortening of Spycraft words and phrases of different kinds). Semantics finds out metaphor and metonymy as conversion means of ESP formation. The most frequently occurring metaphors across ESP are those of personification, process, container, time, animation and orientation. Metonymy is used among the ESP to figuratively name facts from espionage activity. All the ESP linguistic peculiarities are clearly illustrated by a large number of up-to-date examples derived from various English language open access resources. These examples were carefully singled out and collected as a research vocabulary corpus to be entered into the dictionary being prepared for the publication in the nearest future.
\end{abstract}

Keywords: English Spycraft terms; espionage; compounding; affixation; abbreviation; metaphor; metonymy.

\section{Introduction}

In today's turbulent world of ongoing war conflicts between nations, parts of nations and terrorist organisations, security issues have come forth as never before. It has been obvious from ancient times, that a victory over any type of enemy cannot be won by military force alone. It requires a combination of various sophisticated techniques and means allowing for outthinking by the enemy and, thus, preventing or reacting to the enemy's hostile actions. This can be achieved by a well-organised intelligence system where human intelligence or Spycraft is an important part.

Spycraft is the whole world on its own, a very secret business of espionage involving various actors, means and techniques of collection, analysis and dissemination of information critical to policymaking. As in any other job, it has its own language - words and phrases used in this undercover world and little recognised to most of the public; usually taken from novels and films of the 'cold war era'. English, as the official language of the UK and the USA - the countries traditionally having the most powerful intelligence communities in the world, - is rich in Spycraft vocabulary which has been rarely researched.

In this area, we find very rare publications of scholars, mostly of very limited ESP glossaries, compiled for practical reasons (Carl, 1990; Latysheva \& Skulish, 2011; Wallace \& Keith Melton, 2008, pp. 474-480). Large theoretical basis for researching professionalisms can, though, be found in other areas of human trade (Martyanov \& others, 2017; Nurkhamitov \& Fakhrutdinova, 2017). Overall, the ESP has never been fully studied by scientists. They pose an interesting vocabulary body requiring a thorough linguistic research that can further contribute to the areas of lexicology and lexicography thus meeting the practical needs of national security professionals.

The objective of this paper is to define the ESP, provide their classification, as well as to analyse and exemplify their morphological and semantic peculiarities.

\section{Material}

The research is based on 350 lexical units representing typical examples of ESP, collected from a number of literary sources, memoirs, intelligence dictionaries, encyclopedias and open access online resources of British and American official documents and glossaries in the area of Spycraft. 


\section{Methods}

According to the objective of the research, we applied such general scientific methods as study of the research works on the issues of lexicography, terminology, military terminology and colloquialisms as well as other areas of applied linguistics. We also used data collection as a method that allows deriving ESP from the research material. Then comprehensive morphological and semantic analyses of the ESP units were applied. These methods made it possible to reach the objective of the research.

\section{Results and Discussion}

\section{Definition and Classification}

The initial analysis of English Spycraft words and phrases, collected from the above-mentioned material, poses a reasonable question: why do we call these lexical units professionalisms? A closer look at them prompts us some grounds to regard it as terminology or slang. In reality, it is not so.

According to the definitions of 'terms' in the popular reference books and encyclopedias, such types of lexical units are designed to precisely represent notions pertaining to a certain science or area of professional knowledge (Marouzeau, 2004, p. 309-309; Skopnenko \& Tsymbaluik, 2007, pp. 409-410 ). To confirm this, M. Latu as the follower of 'scientific concept of terminology' stresses the fact that a lexical unit can be called 'term' only if it denotes a notion in the scientific discourse (Latu, 2009, pp. 7-8). This requires precise definition of such vocabulary and their official entry into dictionaries. Besides, terms should be stylistically neutral, have no synonyms and should not depend on the context in their meanings (Tsytkina, 1988, p. 11).

On the contrary, Spycraft vocabulary units have no precise definitions, thus, their meanings vary according to the context they are used in. A good example of this is the word 'target' which changes its meaning depending on the type of espionage operation conducted. So, it can be 'a subject for surveillance/counter-surveillance' or 'a person of interest for further development'.

The Spycraft vocabulary is rich in synonyms with different connotations. For instance, a well known word 'informer' in the meaning of 'an individual who provides information on certain location' has at least four known synonyms such as 'informant/snitch/squealer/singer/stool pigeon' (some of these have slightly different emphases in terms of meaning and usage outside Spycraft discourse).

Moreover, the majority of these lexical units are considered terms in other areas of professional knowledge or words from general English, used in the Spycraft business, mostly for the reasons of similarity of concepts they stand for. For example, a 'car pick-up' is a part of everyday English which means ' $g$ etting a person into the car to give him/her a drive', while in the Spycraft language it means 'clandestine meeting with an agent, while driving a car on a route'. Another good example is 'operational report' which comes from purely military language in the meaning of 'report for military operations'. Similarly, it is used in Spycraft to define a 'report on espionage operations'.

Looking at the Spycraft vocabulary we can refer to some of its units as slang, defined as "informal substandard emotionally coloured professional language" (Balabin, 2002, p. 23) The example are such words as 'hare' in the meaning of a 'subject under surveillance', 'tail' which is an informal name for 'surveillance' itself, or 'to do a write-up' which is very colloquial for 'preparing any written documents (reports, plans, descriptions, instructions) for the espionage operations'. Here, we can also spot idioms such as 'devil is in the detail' - a saying often used by case officers to underline the idea of very detailed and thorough elaboration of any espionage operation; or 'you have to kiss a lot frogs before you find your prince' - a proverb which demonstrates a long process of approaching many people before finding the right one to be an agent.

As we can see, on the one hand, the exterior composition of such words and phrases demonstrates vividly their informal nature, while, on the other hand, more and more lexical units like these are being used as official 'terms' in the world of Spycraft. In this connection, it is hard to enter such vocabulary into official dictionaries unless it is standardised and agreed with all the experts using it for professional purposes, which seems impossible in terms of high level of secrecy.

This brief analysis shows an idea that under the vocabulary of our research we can place the various types of units (from unofficial and very colloquial to very standard and terminology-like units) used by the people involved in espionage.

Therefore, based on these grounds, we find it more reasonable to call the vocabulary we research as English Spycraft Professionalisms (ESP). We define them as the lexical units being in transition from general English to the field of terminology. We regard ESP as a system of special semi-official lexical units in their graphic and verbal representation spread across espionage trade area and used to nominate the five basic categories of Spycraft-related issues. 
The first category includes the vocabulary nominating espionage activities, actions and processes connected with running the whole Spycraft business i.e. using humans for gathering critical intelligence, e.g., cultivation - developing an individual into cooperation with the intelligence service; recruitment - getting an individual work for an intelligence service.

This category also includes activities for providing support and security of espionage operations, e.g., personal surveillance detection - measures taken by people involved in espionage activities to verify and identify those who may professionally observe their actions; targeting - spotting a person who is suitable for working as an agent as well as collecting some personal data on him/her; recceing - studying the area of Spycraft operations on the ground.

The second category encompasses terms for denoting actors/subjects of espionage, particularly those directly involved into espionage activities, e.g., agent/source - an individual, typically a foreign national, who works clandestinely for an intelligence service; case officer/source handler - an intelligence officer responsible for running agents; walk-in/volunteer - a person who voluntarily approaches an intelligence agency to offer his/her services; and those providing espionage support and security, e.g., surveillance team - a group of operatives acting together to keep an eye on a person of interest and collect evidence about his/her espionage actions.

Special vocabulary in this category is used to denote qualities or features of the actors/ subjects of espionage, e.g., access - a characteristic of a possible agent testifying his ability to provide secrets for the foreign intelligence; suitability - a reliability of a possible agent.

The third category of our ESP classification encompasses means, instruments/tools of espionage, e.g., legend/cover story - a carefully constructed plausible narration to conceal individual's intelligence actions; recognition signal - a prearranged sign the unfamiliar people involved in espionage use for each other's identification before coming into a contact meeting.

The fourth category includes places/locations for espionage activities, e.g., operational clandestine premises - equipped and arranged secure places for agents meetings; on-the-move-opportunity - a place where an agent or case office can check whether he/she is under surveillance on the route without stopping; station - a secret organisation set up in a foreign country under diplomatic or any other cover including case officers and their support to conduct espionage.

The fifth category demonstrates the vocabulary denoting the product/outcome of the Spycraft activities, e.g., meet material - secrets passed to the case officer by the agent after their meeting; intelligence report - a written account of the information received from a source.

So, as analysed above, due to incongruence of the English Spycraft vocabulary to the majority of 'terminology' features we define them as ESP. They fall into five categories, each one representing the WHAT, WHO, HOW, WHERE, and WHY aspects of Spycraft.

\section{Morphology}

As any other type of vocabulary, ESP can be changed morphologically. Linguistics considers morphological derivation as the process through which a new word is built from a basis, usually, by means of affixes. The most frequent ways of ESP formation, we spotted in the vocabulary under our research, are compounding, affixation, and abbreviation.

Compounding is the combination of nouns, adjectives, verbs, adverbs or prepositions to form complex phrases. About $95 \%$ of the ESP selected for our research are compounds, e.g., source handling unit operational unit; team-based surveillance detection - identification of surveillance by the group of trained and equipped operators.

Affixation (adding prefixes and suffixes) is less spread across ESP. Our analysis shows that the most frequent prefixes used among this type of professionalisms are anti- and counter- - those of Latin origin, expressing opposition, e.g., anti-surveillance - measures, taken by a case officer or an agent against surveillance (to detect surveillance); anti-surveillance route - a prearranged journey an agent or case officer follows to detect surveillance; counter-surveillance - measures, taken by a surveillance team to support a case officer or an agent by detecting hostile surveillance (to detect surveillance); counter-surveillance route - a prearranged road an agent or case officer follows supported by a surveillance team in order to detect hostile surveillance. Less frequent is the prefix dis- in the meaning of 'deducing something', e.g., to discount surveillance positions - to consider the location of surveillance at certain places not good. Sometimes we come across Spycraft notions with prefixes in-, ex- and under-, virtually meaning 'direction', e.g., infiltration - getting into, penetration; exfiltration - getting out, evacuation; undercover - secret, unknown. 
If we have a look at the suffixes, we can notice the following picture: on the one hand, suffixal morphemes help to form new ESP, and, on the other hand, they are also used to form different parts of speech within the whole ESP corpus.

Suffixes can create nouns, most often by attaching to verbs and (to a lesser degree) adjectives. The most typical noun-verb forming suffixes we refer to in ESP are the following:

-age (an espionage action, process, or its result; a thing or place used for this), e.g., to cover escape routes - escape routes coverage (to control ways the subject can split off from surveillance);

-ation; -ment (a state, condition, action, process, or practice in the area of Spycraft, or the result thereof), e.g., to validate an agent - agent validation (estimation of an agent as to his/her meeting professional requirements); to corroborate intelligence - intelligence corroboration (to check and confirm from other sources that the information is true);

-er; -ant (a person or thing performing or capable of a particular espionage action), e.g., to handle sources - source handler (to manage agents); surveil - surveillant (surveillance member);

-ance; -(i)ty; -ness (an action, process, state, condition, trait or quality pertaining to Spycraft) e.g., to surveil - surveillance (keeping an eye on a person); to suit - suitability (agent's reliability).

Our research has revealed that the most common way of making new ESP adjectives out of nouns and verbs is by adding the suffix -able, e.g., action - actionable intelligence (valuable information); to recruit target - recruitable target (a suitable individual to be recruited as an agent).

An interesting way of ESP formation is abbreviation (shorting of words or phrases). There are four different types of abbreviations we can observe within lexical units of our research, namely:

initialisms, basically formed from the first letters of a group of words, each letter pronounced individually, e.g., $C O$ - case officer; $C T R$ - close target reconnaissance (search of subject's any location (house etc.) without official permission in order to find evidence about his/her activity);

acronyms, lexical units formed from the initial letters of a group of words. In this case, the acronym is pronounced as a new word, e.g., PEACE - Planning and Preparation, Engage and Explain, Account, Challenge or Closure, Evaluation (initial letters for basic stages used in questioning agents); SCRIM - Size, Colour, Registration, Identification Marks, Make and Model (initial basic elements for vehicle description used in espionage activities);

shortenings (clippings), i.e. abbreviations in which the beginning or end of the word has been omitted, e.g., intel-intelligence; recce - reconnaissance;

fusion (usually of two words), i.e. humint - human intelligence.

So, abbreviation is a very productive way of making new ESP, basically for two reasons: firstly, English is a very concise language and all the long word expressions tend to be used in the shortest way possible; secondly, Spycraft, being a very secret business, abbreviations are the means for concealing genuine meaning of its vocabulary from people outside this business.

In overall, the morphological analysis has established compounding, affixation and abbreviation as the most widely spread ways of ESP formation.

\section{Semantics}

The semantic ESP analysis objective of our research was to establish ways the lexical units are formed in the Spycraft professional discourse.

In this regard, we find conversion as a most frequently used way of building new ESP. Conversion, as a linguistic concept, envisages formation of new lexical units through its transformation into different parts of speech. In other words, the ESP gain new unequivocal meaning as a result of the secondary nomination. Consequently, the lexical units from a different area of expertise, in most cases, lose their original meanings and get their new significance as ESP.

The best example of conversion is metaphor, which seems ubiquitous across ESP trade. In this connection, our research is substantially supported by a number of studies of metaphors in security discourse by scholars, who present interesting data with reference to their conventionality (Dunn Cavelty, 2013; Hunter \& MacDonald, 2017; Lule, 2004). Guided by the ideas of the 'cognitive structure of a conventional metaphor' proposed by Lakoff \& Johnson (2008) and Kövecses (2010), we split all the metaphors into six basic groups as follows. Here, we also provide examples for better illustrating them with reference to sources they are derived from.

The first group represents a metaphor of personification (i.e. when an ESP element acquires human traits), e.g., 
At that meeting Fuchs was given detailed instructions on dead-letter box in Richmond, where he was instructed to toss a magazine onto the garden lawn with his message written on page ten (West, 2016, pp. 205-211).

In the above-mentioned example, we can clearly see how a non-living being gets the features pertaining to a living being only. The 'letter box' cannot be dead and is used as a personification metaphor in the meaning of 'method of covert communications between an agent and case officer'.

Second is a metaphor of process. It indicates the occurrence of a process e.g.,

He failed to pick up surveillance directed against him, failed to hide adequately the money the Russians gave him, and he was obviously trying to beat the polygraph when the time came for a security review (Hulnick, 1997).

Actually, we cannot 'pick up surveillance', which is a 'process of observation', but, here, the verb 'pick up' is used as a metaphor of process in the meaning of 'spotting surveillance'. In the same way, literally, it is impossible 'to beat the polygraph', which is metaphorically 'the process of evading a lie detector'.

The third group includes a metaphor of container (it implicates an imaginary container) e.g.,

A technique known as a surveillance box was used to successfully conduct longer-term covert surveillance. The surveillance team boxed him in at a stop sign (Brocklehurst, 2016, p. 67).

Here, we can observe an interesting example of how the meaning of the word 'box' with a feature of 'surrounding someone or something' is metaphorically transferred into a new ESP meaning of a 'surveillance technique, used to place operators to surround a subject' - virtually in a box.

Next is a metaphor of time which refers to a chronological period or an expression of time e.g.,

Fallback time is a pre-arranged repeat time for carrying out a planned operation in the event that the operation is not carried out for any reason (Mitrokhin, 2002).

An example of 'fallback time', which sounds non-sense out of the Spycraft context, clearly demonstrates, how meaning is metaphorically transferred into that of 'reserve time'.

The fifth group is made up of metaphors of animation (when an element of a lexical unit acquires animal traits), e.g.,

Chamberlain even had MI5 tail him for a time (Hyde Jr, 2005);

For surveillance field exercise our class divided into groups of hares and hounds (Duval, 2008, p. 17).

These examples show some animal traits ('tail' as a part of animal body always following it) or names of animals ('hare' in the meaning of a weak animal hunted down by 'hounds', i.e. dogs running after it in order to catch) are used to express basic features of the Spycraft actors and actions such as 'surveillance', 'subject under surveillance' and 'surveillance operators'.

The sixth group includes an orientation metaphor. This type of metaphor occurs among ESP in order to organise a whole system of concepts with respect to one another. Most of these metaphors have to do with spatial orientation. Analysing them, we made an attempt to give a hint of where each metaphorical concept might have come from.

The largest number of these ESP are those having the meaning of 'direction' ('up' and 'on' used with verbs or nouns in meaning of 'having or getting control over something or somebody' as well as in the meaning of 'something unknown') e.g., to pick up surveillance (to spot and control surveillance); lock-on (a location point used by surveillants for orientation); setup (a person provided by counterintelligence (unknown to intelligence) and later discovered as that working for the enemy). On the contrary, verbs with 'down' are used in the meaning of 'to deprive somebody of something', e.g., to tie secret services down (to prevent secret services from working properly).

As we can see through multiple recurrences, metaphors can finally get conventionalised and, therewith, become a part of the language norm in the Spycraft context. In view of the fact that metaphors are culturespecific and also reveal patterns of thoughts that characterise a Spycraft professional language, a big deal of them in one domain (outside Spycraft) can be considered as "dead" (standard) metaphors and "living" (novel) within Spycraft business. Here are some examples of "dead" metaphors in other areas of human knowledge extracted from a research vocabulary bodys, e.g., dry clean - to get rid of the surveillance (originally comes from dry cleaners' business); elastic stop - a natural stop on the route allowing a case officer or agent to save time and not to draw suspicion before coming into contact (originally from aviation); brush contact - a brief contact between an agent and case officer during which an exchange of physical material, such as secret documents, money etc. occurs (originally, from the area of electric engines).

Besides the metaphor of different types, we can also spot metonymy in the ESP. Less frequently, though, it is used to represent figurative facts of reality. We can also notice that there are very few one-word lexical units formed by means of metonymic translation. Their combination with adjectives gives a significant number of multi-component ESP. Thus, this kind of lexical-semantic method of generating ESP practically 
always interacts with syntactic formation. Examples of such interaction in ESP include a large number of multi-component names created by means of metonymic translation, e.g., four fingers - basic elements that should be covered in the meeting of an agent with his/her case officer; defensive service - another name for MI5, a British counterintelligence; ten-to-two - a surveillance observation range.

Thus, the ESP semantic analysis demonstrates conversion, represented by metaphor and metonymy as the basic way of their formation. Their examples testify how linguistically diverse the lexical units are in the professional discourse of the most secret job in the world.

\section{Conclusions}

The research presents a comprehensive analysis of ESP as a linguistic phenomenon, based on the collected vocabulary of 350 lexical units. It was established that these lexical units can be placed under the category of 'professionalisms' because they do not meet the 'terminology' requirements in full scope, in terms of preciseness of their definitions; changeability of meaning depending on the context as well as stylistic markings. In overall, we define ESP as a wide range of more or less official Spycraft-related vocabulary falling into the five basic categories: espionage activities, actions and processes; actors/subjects; instruments/tools of espionage; places/locations; product/outcome. The vocabulary examples provided clearly illustrate each category.

The morphological analysis shows compounding, affixation, and abbreviation as the basic ways of ESP formation. Compounding is widely spread among the whole vocabulary body making one-word components extremely rare. Affixation, though less frequently occurring, is used to both create new lexical units as well as to transform parts of speech. The affixation peculiarities of ESP include wide usage of such prefixes as anti- and counter- (meaning 'opposition'), dis- (meaning 'deducing something'), in-, ex- and under(meaning 'direction') and such suffixes as -age; -ation; -ment; -er; -ant; -ance; -(i)ty; -ness to transform verbs (or adjectives) into nouns, and suffix -able to make adjectives from nouns. At the same time, in order to make the English Spycraft language more concise and hide its true meaning, we also find abbreviation as a very productive way.

The semantic analysis reveals conversion as the basic way of ESP formation represented by different types of metaphors, namely, personification, process, container, time, animation and orientation. Besides, here we can also observe "dead" (standard) and "living" (novel) metaphors: those having lost their meaning in other areas and having got a new one in Spycraft. Moreover, second to metaphors among ESP is metonymy, a linguistic technique, used to represent figurative facts of espionage reality. All the vocabulary examples provided can vividly illustrate diversity of ESP metaphors and metonymy.

In overall, ESP turns out a unique linguistic phenomenon. Despite our linguistic analysis, there still remain some areas for further research that, in our belief, are focused on practical issues of compiling ESP dictionaries.

\section{References:}

Balabin, V. V. (2002). Suchasnyi amerykanskyi viyskovyi slenh jak problema perekladu [Contemporary American Military Slang as a Problem of Translation]. Kyiv: Logos.

Carl, L. D. (1990). International Dictionary of Intelligence. Virginia: International Defense Consultant Services.

Cavelty, M. D. (2013). From Cyber-bombs to Political Fallout: Threat Representations with an Impact in the Cyber-security Discourse. International Studies Review, 15(1), 105-122. https://doi.org/10.1111/misr.12023.

Duval, A. E. (2008). Jungle and Other Tales: True Stories of Historic CI Operations. Tucson: Wheatmark.

Hulnick, A. S. (1997). Intelligence and law enforcement: The "spies are not cops" problem. International Journal of Intelligence and Counterintelligence, 10(3), 269-286: https://doi.org/10.1080/08850609708435350 .

Hunter, D. \& MacDonald, M. (2017). The Emergence of a Security Discipline in the Post 9/11 Discourse of US Security Organisations. Critical Discourse Studies, 14(2), 206-222. https://doi.org/10.1080/17405904.2016.1268185.

Hyde Jr., E. M. (2005). Churchill's Personal Spies. International Journal of Intelligence and Counterintelligence, 18(2), $305-319$. https://doi.org/10.1080/08850600590911963

Kövecses, Z. (2010). Metaphor: A Practical Introduction. Oxford: Oxford University Press.

Lakoff, G. \& Johnson, M. (2008). Metaphors we live by. Chicago: University of Chicago Press.

Latu, M. N. (2009 Anglojazychnaja vojennaja terminologija $v$ istoricheskom razvitii: strukturno-semanticheskiy $i$ kognitivnofrejmovyi aspekty [English Military Terminology in its Historic Development: Structural Semantic and Cognitive Framework Aspects]. Unpublished candidate dissertation, Rostov-on-Don, Russia.

Latysheva, N., \& Skulish, E. (2011). Glossary of Security Services Tradecraft Slang. Kyiv: NSSAU.

Lule, J.( 2004). War and its Metaphors: News Language and the Prelude to War in Iraq. Journalism Studies, 5(2), 179-190: https://doi.org/10.1080/1461670042000211168.

Martyanov, D. A., Galiullin K. R., \& Gorobets, E. A. (2017). The Core of Professional Language in Terminographic Representation (based on the special vocabulary of the medical sphere). Modern Journal of Language Teaching Methods, 7(10), 31-36. Retrieved January, 5, 2018, from Modern Journal of Language Teaching Methods website, http://mjltm.org/files/cd_papers/r_455_171128104731.pdf

Marouzeau, J. (2004). Lerxique de la terminologie linguistique [Dictionary of Linguistic Terms]. Moscow: URSS. 
Mitrokhin, V. (2002). KGB Lexicon: The Soviet Intelligence Officers Handbook. Abingdon: Frank CASS and CO

Nurkhamitov, M. R. \& Fakhrutdinova, A. V (2017). Features of Teaching Professionally Oriented Vocabulary of Students in the Large Groups (by the Example of Faculty of Law). QUID: Investigación, ciencia y tecnología, 1, 400-404, Retrieved January, 5, 2018, from QUID web site, http://revistas.proeditio.com/iush/quid/issue/view/122

Skopnenko, O. I., \& Tsymbaluik, T. V. (2007). Mala filolohichna entsyklopedija [Small Linguistic Encyclopedia]. Kyiv: Dovira.

Tsytkina, F. A. (1988). Terminologiya i perevod [Terminology and Translation]. Lvov: Vischa Shkola.

Wallace, R., \& Keith Melton H. (2008). Spycraft. The Secret History of the CIA's Spytechs from Communism to Al-Qaeda. New York: Penguin Group.

West, N. (2016). Knaves or Fools? David Aaronovitch: Party Animals My Family and Other Communists. London: Jonathan Cape.

Received: January 22, 2018 Accepted: April 27, 2018 